\title{
Correlation Between Physical Activity Measured by a Wearable Device and Quality of Life in Older Adults
}

\author{
Si-hyun Kim, PT, PhD \\ Department of Physical Therapy, Sangji University, Wonju, Korea
}

\author{
Article Info \\ Received September 30, 2021 \\ Revised October 15, 2021 \\ Accepted October 16, 2021

\section{Corresponding Author} \\ Si-hyun Kim \\ E-mail: sihyunkim0411@gmail.com \\ https://orcid.org/0000-0003-1870-2767
}

\section{Key Words}

Aged

Physical activity

Quality of life

Wearable electronic devices
Background: Physical activity and quality of life (QOL) influence the health status of older adults. Recently, the use of wearable devices to monitor physical activity has increased.

Objects: This study examined the relationship between the amount of physical activity, measured using a wearable device, and QOL among older adults.

Methods: In total, 71 older adults (aged $\geq 65$ years) were enrolled. The amount of physical activity was measured using a wearable device with a wrist strap, and daily physical activity was classified according to intensity (sedentary, light, moderate, or very active). Self-reported QOL was evaluated using the Short Form 36 (SF-36) questionnaire. Pearson and Spearman correlation analyses were conducted to analyze parametric and non-parametric variables, respectively. The relationship between amount of daily physical activity and SF-36 scores was assessed.

Results: The correlation analyses revealed positive correlations between the amount of moderate-intensity and very active physical activity (minutes/day) and SF-36 scores ( $p<0.05$ ).

Conclusion: Physical activity of at least moderate intensity is associated with better QOL in older adults. Further studies are required to verify the effects of increased physical activity on QOL in older adults.

\section{INTRODUCTION}

Physical activity is vital to maintain and promote physical, psychological, and cognitive health [1-4]. Decreased physical activity is related to an increased risk for chronic disease, disability, and mortality [1,5]. However, older adults often exhibit insufficient physical activity, i.e., failure to meet the amount of moderate-intensity activity recommended by the World Health Organization (150 min/week) [6,7].

Health-related quality of life (QOL) is an important predictor of overall health status; low QOL is related to impairment and functional limitations [8]. Older adults report decreased QOL in association with depression, low financial status, limited mobility, and longstanding illness [9]. The Short Form 36 (SF-36) questionnaire, used to evaluate health-related QOL, consists of eight dimensions: physical functioning, role limitations due to physical function, bodily pain, general health, mental health, role limitations due to emotional health, social functioning, and vitality $[10,11]$. It can be utilized to examine the effectiveness of interventions aimed at improving health status, both in the clinical setting and in experimental studies, in diverse population including those with diseases.

Wearable devices fitted to the wrist are useful for monitoring levels of physical activity. These devices can interface with mobile phones or computer software, and users can receive feedback regarding their physical activity behavior; this can facilitate positive changes in physical activity levels. In addition, physical activity data measured by wearable devices are more objective than self-reported physical activity data. This study assessed the relationship between the amount of physical activity, as measured via wearable devices, and QOL in older adults. 


\section{MATERIALS AND METHODS}

\section{Participants}

Data were collected from 71 participants recruited from a local community in Wonju-si, South Korea. The inclusion criteria were as follows: aged $\geq 65$ years, living in the community, and no cognitive problems (i.e., ability to understand the study procedure). This study excluded individuals with poor balance or ambulation due to musculoskeletal and/or neurological disease, and those with dizziness or breathing difficulties. All participants signed an informed consent form after confirming that they understood all of the study procedures. This study was approved by the Institutional Review Board of Sangji University.

\section{Quality of Life}

This study used the SF-36 questionnaire to measure selfreported QOL [11]. The SF-36 consists of 36 items and eight dimensions, with the dimensions further grouped into two components: physical and mental. The score range is $0-100$, where higher scores reflect better perceived QOL. The scores for the physical and mental components, and the sum score for both components, were calculated in this study.

\section{Physical Activity}

All participants wore the Alta HR device (Fitbit, San Francisco, CA, USA) on their wrists to measure the amount of physical activity per day (Figure 1). On day 1, a researcher explained how to wear and charge the device. All participants were required to wear the Alta HR device at all times during a 7-day period, except when showering or charging the battery. The

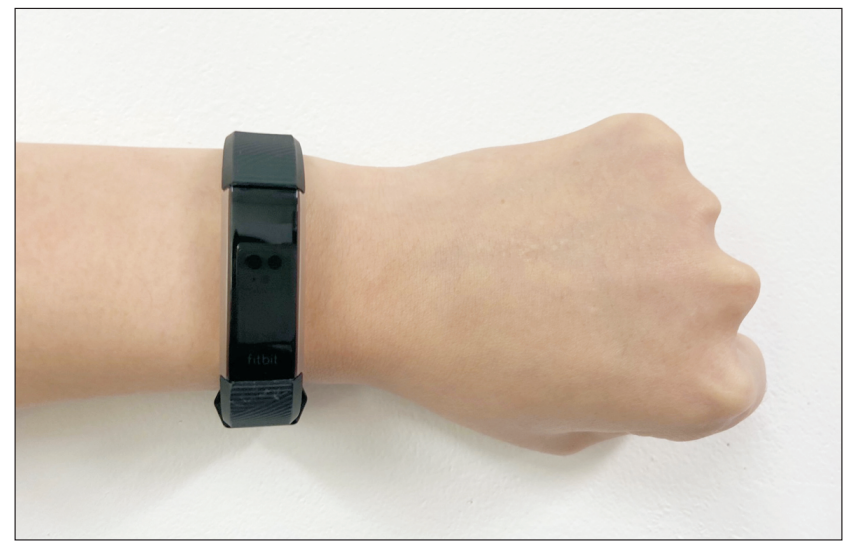

Figure 1. Wearing the Alta HR (Fitbit, San Francisco, CA, USA) device.
Alta HR device uses a triaxial accelerometer and collect raw acceleration signals. The collected data were imported into the Fitabase program (Small Steps Labs, LLC, San Diego, CA, USA) and the amount of physical activity per day was classified according to activity intensity [12]. Sedentary was defined as < 1.5 metabolic equivalent of tasks (METs), light as $\geq 1.5$ and $<$ 3 METs, moderate as $\geq 3$ and $<6$ METs, and very active as $\geq 6$ METs. Outcomes included mean minutes per day in each activity intensity. Participants lacking data for at least 4 days were omitted from the analysis.

\section{Statistical Analysis}

SPSS for Windows software (ver. 26.0; IBM Co., Armonk, NY, USA) was used to analyze the data. All descriptive data are provided as mean \pm standard deviation. The normality of the data was assessed using the Shapiro-Wilk test. Associations between daily activity intensity and SF-36 scores (total, and physical and mental components) were analyzed by Pearson's correlation for parametric variables and Spearman's correlation for nonparametric variables. A good-excellent correlation corresponded to a correlation coefficient $(r)$ of $>0.75$, moderate-good to an $r$ value of $0.50-0.75$, fair to an $r$ value of $0.25-0.49$, and little or none to an $r$ value of $0.0-0.24$ [13]. The significance level for all analyses was set to $\mathrm{p}<0.05$.

\section{RESULTS}

The characteristics of the participants are described in Table 1. Table 2 shows the SF-36 scores and amount of physical activity of the participants. Table 3 shows the correlations between the daily amount of physical activity and SF36 scores. Moderate activity showed fair correlations with the total $(r=0.462, p<0.001)$ and mental $(r=0.331, p=0.005) S F-$ 36 component scores, and a moderate-good correlation with the physical $(r=0.514, p<0.001)$ SF-36 component score. The

Table 1. Participant characteristics ( $N=71)$

\begin{tabular}{lc}
\multicolumn{1}{c}{ Variables } & Values \\
\hline Sex (male/female) & $32 / 39$ \\
Age (y) & $72.37 \pm 4.95$ \\
Weight $(\mathrm{kg})$ & $62.63 \pm 10.16$ \\
Height $(\mathrm{cm})$ & $160.07 \pm 9.61$ \\
Body mass index $\left(\mathrm{kg} / \mathrm{m}^{2}\right.$ ) & $24.42 \pm 3.31$ \\
Mini-mental state exam (scores) & $28.18 \pm 1.51$
\end{tabular}

Values are presented as number only or mean \pm standard deviation. 
Table 2. Mean and standard deviation SF-36 of scores and amount of physical activity

\begin{tabular}{lc}
\hline \multicolumn{1}{c}{ Variables } & Mean \pm standard deviation \\
\hline SF-36 (scores) & $67.12 \pm 13.22$ \\
Total & $66.69 \pm 14.85$ \\
Physical & $67.57 \pm 13.76$ \\
Mental & \\
Physical activity (minutes/day) & $721.62 \pm 116.51$ \\
Sedentary & $221.76 \pm 75.00$ \\
Lightly & $22.11 \pm 19.92$ \\
Moderate & $24.45 \pm 22.57$ \\
Very active & \\
\hline
\end{tabular}

SF-36, Short Form 36.

very active level of activity showed fair correlations with the total $(r=0.370, p=0.001)$ and physical $(r=0.444, p<0.001)$ and little or no correlation with mental $(r=0.243, p=0.041)$ SF-36 scores. However, there were no significant correlations between the sedentary and light activity levels with any SF-36 scores.

\section{DISCUSSION}

This study examined the relationship between physical activity and QOL in older adults (aged $\geq 65$ years). Fair and moderate-good correlations of moderate and very active physical activity levels with QOL were observed.

Self-reported health-related QOL is an important indicator of mortality in older adults. Similar to a previous study, this study found that older adults with higher levels of physical activity (moderate or very active) had higher life satisfaction, particularly in terms of the physical component of the SF-36 $[14,15]$. Inactivity in older adults is associated with depression and physical limitations, whereas sports and social activities promote overall well-being [16-18]. Older adults (aged $\geq 55$ years) reported perceived environmental, motivational, and physical barriers (e.g., physical disabilities related to chronic disease) to physical activity; these barriers were associated with less physical activity [19]. Although this study showed fair and moderate-good correlations between physical activity and QOL, this study suggests that physical activity of at least moderate intensity such as a walking 3.0 miles per hour, water aerobics, or general gardening may be considered to improve perceived QOL in older adults [20].

Wearable device is useful and acceptable to monitor and assess physical activity pattern. In addition, real-time feedback
Table 3. Results of the linear correlation analysis

\begin{tabular}{lccc}
\hline & Total SF-36 & $\begin{array}{c}\text { Physical } \\
\text { component }\end{array}$ & $\begin{array}{c}\text { Mental } \\
\text { component }\end{array}$ \\
\hline Sedentary & -0.041 & -0.049 & -0.016 \\
Lightly & 0.019 & 0.025 & 0.059 \\
Moderate & $0.462^{* *}$ & $0.514^{* *}$ & $0.331^{* *}$ \\
Very active & $0.371^{* *}$ & $0.444^{* *}$ & $0.243^{*}$ \\
\hline
\end{tabular}

SF-36, Short Form 36. ${ }^{*} p<0.05,{ }^{* *} p<0.01$.

of the wearable devices based on interface with mobile phone or computer could facilitate and promote physical activity [21]. Previous Wearable devices are useful for monitoring and assessing physical activity patterns. Real-time feedback from these devices, via a mobile phone or computer, may promote physical activity. Previous studies have demonstrated that individuals aged $\geq 60$ years with impaired health status (e.g., with hypertension, cardiovascular disease, or diabetes) perceive smart wearable devices as useful and intend to use them (e.g., accelerometers, skin electrodes, piezoelectric sensors, and so forth) $[22,23]$. Thus, older adults appear to be willing to use wearable devices to monitor their physical health, with the expectation of improving their health status. This study recommends monitoring physical activity patterns of older adults can be monitored through wearable devices; future studies should assess the capacity of these devices for increasing physical activity and improving QOL in older adults.

This study had several limitations. First, it used a crosssectional design, so this study could not infer causality in the relationship between physical activity and QOL. In addition, this study did not consider the effects of sociodemographic characteristics, such as loneliness, perceived social support, and chronic disease (e.g., osteoporosis and stroke), on healthrelated QOL [24,25]. Further study is needed to examine the relationship between physical activity and QOL while controlling for the sociodemographic characteristics of older adults. Despite these limitations, this study demonstrated an association between physical activity, as measured via wearable devices, and health-related QOL in older adults.

\section{CONCLUSIONS}

This study found an association between amount of moderate and very active physical activity and self-reported QOL in older adults. The amount of moderate or very active physical activity was positively associated with self-reported QOL ac- 
cording to the physical and mental components of the SF36, as well as with overall SF-36 scores. Further studies are warranted to verify the changes and improvements in QOL in older adults induced by at least moderate physical activity, as monitored by wearable devices.

\section{ACKNOWLEDGEMENTS}

This work was supported by the National Research Foundation of Korea (NRF) grant funded by the Korea government (MSIT) (No. 2018R1C1B5083305).

\section{CONFLICTS OF INTEREST}

No potential conflict of interest relevant to this article was reported.

\section{REFERENCES}

1. Haskell WL, Blair SN, Hill JO. Physical activity: health outcomes and importance for public health policy. Prev Med 2009;49(4):280-2.

2. Kull M. The relationships between physical activity, health status and psychological well-being of fertility-aged women. Scand J Med Sci Sports 2002;12(4):241-7.

3. Warburton DE, Nicol CW, Bredin SS. Health benefits of physical activity: the evidence. CMAJ 2006;174(6):801-9.

4. Gregory SM, Parker B, Thompson PD. Physical activity, cognitive function, and brain health: what is the role of exercise training in the prevention of dementia? Brain Sci 2012;2(4):684-708.

5. Gregg EW, Cauley JA, Stone K, Thompson TJ, Bauer DC, Cummings SR, et al.; Study of Osteoporotic Fractures Research Group. Relationship of changes in physical activity and mortality among older women. JAMA 2003;289(18):2379-86.

6. World Health Organization. Global recommendations on physical activity for health: recommended levels of physical activity for adults aged 65 and above [Internet]. Geneva: 2010 [cited 2021 Sep 1]. Available from: http://www.who. int/dietphysicalactivity/factsheet_recommendations/en/.

7. Kamimoto LA, Easton AN, Maurice E, Husten CG, Macera CA. Surveillance for five health risks among older adults-United States, 1993-1997. MMWR CDC Surveill Summ 1999;48(8):89-130.
8. Stuifbergen AK, Blozis SA, Harrison TC, Becker HA. Exercise, functional limitations, and quality of life: a longitudinal study of persons with multiple sclerosis. Arch Phys Med Rehabil 2006;87(7):935-43.

9. Netuveli G, Wiggins RD, Hildon Z, Montgomery SM, Blane D. Quality of life at older ages: evidence from the English longitudinal study of aging (wave 1). J Epidemiol Community Health 2006;60(4):357-63.

10. Lyons RA, Perry HM, Littlepage BN. Evidence for the validity of the Short-form 36 Questionnaire (SF-36) in an elderly population. Age Ageing 1994;23(3):182-4.

11. Han CW, Lee EJ, Iwaya T, Kataoka H, Kohzuki M. Development of the Korean version of Short-Form 36-Item Health Survey: health related QOL of healthy elderly people and elderly patients in Korea. Tohoku J Exp Med 2004;203(3):189-94.

12. Dominick GM, Winfree KN, Pohlig RT, Papas MA. Physical activity assessment between consumer- and research-grade accelerometers: a comparative study in free-living conditions. JMIR Mhealth Uhealth 2016;4(3):e110.

13. Portney LG, Watkins MP. Foundations of clinical research: applications to practice. Upper Saddle River: Pearson/Prentice Hall; 2009

14. McAuley E, Konopack JF, Motl RW, Morris KS, Doerksen SE, Rosengren KR. Physical activity and quality of life in older adults: influence of health status and self-efficacy. Ann Behav Med 2006;31(1):99-103.

15. Lustyk MK, Widman L, Paschane AA, Olson KC. Physical activity and quality of life: assessing the influence of activity frequency, intensity, volume, and motives. Behav Med 2004;30(3):124-32.

16. Gomes M, Figueiredo D, Teixeira L, Poveda V, Paúl C, Santos-Silva A, et al. Physical inactivity among older adults across Europe based on the SHARE database. Age Ageing 2017;46(1):71-7.

17. Stathi A, Fox KR, McKenna J. Physical activity and dimensions of subjective well-being in older adults. J Aging Phys Act 2002;10(1):76-92.

18. Huxhold O, Miche M, Schüz B. Benefits of having friends in older ages: differential effects of informal social activities on well-being in middle-aged and older adults. J Gerontol B Psychol Sci Soc Sci 2014;69(3):366-75.

19. Clark DO. Physical activity and its correlates among urban primary care patients aged 55 years or older. J Gerontol B Psychol Sci Soc Sci 1999;54(1):S41-8. 
20. U.S. Department of Health and Human Services. 2008 Physical activity guidelines for Americans [Internet]. Washington, D.C.: 2008 Oct [cited 2021 Sep 1]. Available from: http://www. health.gov/paguidelines/pdf/paguide.pdf.

21. Cooper C, Gross A, Brinkman C, Pope R, Allen K, Hastings S, et al. The impact of wearable motion sensing technology on physical activity in older adults. Exp Gerontol 2018;112:9-19.

22. Li J, Ma Q, Chan AH, Man SS. Health monitoring through wearable technologies for older adults: smart wearables acceptance model. Appl Ergon 2019;75:162-9.

23. Chen K, Chan AH. Gerontechnology acceptance by elderly
Hong Kong Chinese: a senior technology acceptance model (STAM). Ergonomics 2014;57(5):635-52.

24. Kang HW, Park M, Wallace Hernandez JP. The impact of perceived social support, loneliness, and physical activity on quality of life in South Korean older adults. J Sport Health Sci 2018;7(2):237-44.

25. Lima MG, Barros MB, César CL, Goldbaum M, Carandina L, Ciconelli RM. Impact of chronic disease on quality of life among the elderly in the state of São Paulo, Brazil: a populationbased study. Rev Panam Salud Publica 2009;25(4):314-21. 